\title{
Production intensification and animal health expenditure on dairy farms in New Zealand
}

\author{
Wanglin Ma, ${ }^{*}$ Kathryn Bicknell, and Alan Renwick \\ Department of Global Value Chains and Trade, Faculty of Agribusiness and Commerce, Lincoln University, Lincoln 7647, Christchurch, \\ New Zealand
}

\begin{abstract}
Although previous studies have investigated the effects of production intensification on farm economic performance and production efficiency in the dairy sector, knowledge is currently lacking on how intensification is related to farmer activities directed toward animal health outcomes. This study addresses the gap in the literature. A fixed-effects model estimated with a panel data set from New Zealand dairy farms is used to analyze the relationship between feed use intensification and animal health expenditure, controlling for a range of confounding effects. The empirical results show that, on average, feed use intensification is associated with a statistically significant increase in health expenditure per cow, and the positive effect is due primarily to the expenditure patterns of the farmers who have adopted the most intensive farming systems. The results also indicate that profitability, as measured by cash surplus, did not appear to be significantly related to the level of animal health expenditure on New Zealand dairy farms between 2005 and 2014.
\end{abstract}

Key words: production intensification, health expenditure, dairy farm, New Zealand

\section{INTRODUCTION}

Agricultural intensification is technically defined as an increase in agricultural production per unit of input such as labor, land, time, fertilizer, seed, supplementary feed, or cash (FAO, 2004; Salou et al., 2017). As land is a strongly limiting input for agricultural production, the trend toward intensification seems unavoidable globally. In the dairy sector, intensification involves different strategies such as increasing off-farm inputs (e.g., fossil fuels, chemical fertilizer, pesticides, and the amount of supplementary feed) and using better plant cultivars that are lower in fiber and higher in protein

Received November 22, 2018.

Accepted September 29, 2019.

*Corresponding author: Wanglin.Ma@lincoln.ac.nz and energy (Lean et al., 2008; Chobtang et al., 2017; Salou et al., 2017). These strategies allow producers to increase stocking rates (the number of cows milked per hectare of land), which is often associated with higher levels of productivity and profitability.

Intensifying pasture-based dairy production has been a global phenomenon and is increasingly significant in dairy producing countries such as New Zealand, Australia, the United States, Brazil, and China. In New Zealand, a feature of the intensification process has been the increased use of feed supplements. Over the past 2 decades, the dairy industry in New Zealand has transformed as these supplements have been increasingly introduced into the traditional pasture-based farming systems. Several reasons for this transformation have been identified, including to increase the volume of production, to respond to seasonal weather patterns, and to react to public pressure concerning animal welfare through a desire to improve cow body condition (Stafford and Gregory, 2008; Mounsey, 2015; Ma et al., 2019a). Increasing attention is being given by researchers and policy analysts to various factors related to intensification because of its association with the social, economic, and environmental performance of dairy farms. To date, 3 strands of literature have emerged.

The first strand relates to the effect of feed intensification on farm economic performance (e.g., Hedley et al., 2006; Yates et al., 2010; Mounsey, 2015; Ma et al., 2018). For example, Ma et al. (2018) found that although increasing input intensity increases milksolids production and gross revenue, it also leads to higher costs, and thus reduces operating profit, operating profit margin, and return on assets. The second strand analyzes the effect of intensification on technical efficiency (i.e., the effectiveness with which a given set of inputs is used to produce an output) of dairy production (e.g., Kompas and Che, 2006; Abdulai and Tietje, 2007; Alvarez et al., 2008; Basset-Mens et al., 2009). In their investigation of the technical efficiency of dairy farms in Australia, for example, Kompas and Che (2006) found that total grains and concentrates used per cow has a positive and 
significant effect on technical efficiency, although the effect was small in absolute value. A study by Ma et al. (2019a) shows that feed use intensification (i.e., intensifying dairy production through using supplementary feeds such as silage, barley, meal, and fodder beet) has a positive and statistically significant effect on technical efficiency of dairy farms in New Zealand.

The third strand investigates the nexus between intensification and environmental performance and argues that production intensification may generate negative environmental effects such as deforestation, biodiversity loss, and greenhouse gas emissions (e.g., Basset-Mens et al., 2009; Bava et al., 2014; Foote et al., 2015; Chobtang et al., 2017; Salou et al., 2017). Generally, these studies show that intensification of dairy farming is detrimental to environmental performance or farm eco-efficiency (i.e., the ability of a system to fulfill a function while minimizing its total effects on the environment). Basset-Mens et al. (2009) found that intensification from the increased use of nitrogen fertilizer or maize silage is detrimental to the eco-efficiency of dairy farms in term of milk production and land use in New Zealand. In their analysis of New Zealand dairy farms, Chobtang et al. (2017) showed that relative to less intensive pasture-based dairy farming systems, more highly intensive systems produce more milk (both per cow and per hectare) but also generate greater negative environmental impacts.

In addition to the financial, efficiency, and environmental implications of feed use intensification, production intensification may be related to farmer engagement with animal health activities, which is of importance for a range of ethical and economic reasons. The objective of this paper is, therefore, to extend previous findings by investigating the association between feed use intensification and per cow expenditure on animal health at the farm level. Although expenditure may be an ambiguous measure of animal health, it is an acceptable indicator of farmer engagement with the health status of their herd. In other words, an assumption of this analysis is that expenditure on animal health is being undertaken to either improve the health status of the individual cow or the herd, or to mitigate or avoid poor animal health outcomes. Livestock systems are complex, and animal health and welfare are closely linked to the socio-economic activities of the people who own and look after them (Rushton, 2011). As recently observed by Sumner et al. (2018), farmers, generally in consultation with their veterinarians, are ultimately responsible for deciding how much to spend on animal health and welfare on their farms. It is, therefore, helpful to better understand the factors that are associated with higher versus lower levels of animal health expenditure at the herd level. Increased knowledge about the association between feed use intensification and animal health expenditure can help improve our understanding of the wider implications of the trend toward increasing intensification in the dairy industry.

The data are sourced from the New Zealand DairyBase database and includes observations from 3,119 farms that appear at least once in the database during a 10-yr period from 2005 to 2014. The length of time that farms are part of the database varies and this means that over the period there are a total of 9,572 observations. A fixed-effects panel data model is used for the empirical analysis. This enables the effect of the time-invariant characteristics to be removed so that it is possible to estimate the net relationship between the independent variables and the dependent variable. The empirical findings of this study can help stakeholders in New Zealand and internationally to develop a better understanding of the range of factors that are associated with expenditure on animal health, with a particular focus on feed use intensification.

\section{MATERIALS AND METHODS}

\section{Data}

The data used in the empirical analysis were extracted from the DairyNZ database, which is owned and managed by DairyNZ on behalf of the dairy farmers in New Zealand. DairyNZ is an "industry good" organization funded by farmers through a levy on milksolids. The dairy farm business data were collected from dairy farms throughout New Zealand through a web-based recording system that facilitates the reporting of standardized physical and financial information from dairy farms. The surveyed farms are located in 3 regions in the South Island (West Coast-Tasman, MarlboroughCanterbury, and Otago-Southland) and 5 regions in the North Island (Northland, Waikato, Bay of Plenty, Taranaki, and Lower North Island), covering the main dairy production regions in New Zealand. We use a sample of 3,119 dairy farms from 2005 to 2014 (forming an un-balanced panel data set of 9,752 observations) for the empirical estimation.

\section{Measurement of Key Variables}

The primary focus of this study is to analyze the relationship between feed use intensification and animal health expenditure. Different indicators such as the ratio of purchased feed to herd size, the average amount of concentrate fed to the cows $(\mathrm{kg} /$ head), levels of feed, and feed expenditure have been employed to reflect feed use intensification or farm system intensity (Kompas and Che, 2006; Abdulai and Tietje, 2007; Cabrera et 
Table 1. Characteristics of 5 production systems in New Zealand ${ }^{1}$

\begin{tabular}{ll}
\hline System $^{2}$ & Characteristic \\
\hline 1 & $\begin{array}{l}\text { Self-contained: no imported feed } \\
\text { No supplement feed purchased, except supplement harvested off the effective milking area and no grazing off the effective } \\
\text { milking area by dry cows }\end{array}$ \\
& $4-14 \%$ of total feed imported \\
2 & Feed imported, either as supplements to milking cows or grazing and supplements for dry cows \\
& $10-20 \%$ of total feed imported \\
& Feed imported, both as supplements to extend lactation (typically autumn feed) and grazing and supplements for dry cows \\
& 20-30\% of total feed imported
\end{tabular}

${ }^{1}$ Source: DairyNZ (2017).

${ }^{2}$ The 5 production systems are mainly categorized based on the timing, purpose, and amount of imported feed used; it is possible that a dairy farm may shift from one system to another system over time.

${ }^{3}$ Following the convention set by DairyNZ, "imported feed" refers to feed eaten by dairy cattle (such as silage, barley, or meal) that is not grazed directly off the effective milking area.

${ }^{4}$ Feed is measured in terms of DM.

al., 2010). However, limitations in the data set preclude the use of these indicators. Following Ma et al. (2019a), we measure feed use intensification as an ordered variable representing 5 production systems. This is both reasonable and practical because the 5 production systems in New Zealand are classified based on the timing, purpose, and amount of imported feed (i.e., feed eaten by dairy cattle that is not grazed directly off the effective milking area). The 5 systems progress from system 1 where there is "zero input of supplementary feed" to system 5 where there is "more than $30 \%$ of feed imported" (DairyNZ, 2017). The characteristics of the 5 production systems are presented in Table 1.

Animal health expenditure per cow is the dependent variable used in the present study. The variable includes expenditure on prevention as well as treatment, and consists of costs such as veterinarian fees and supplies, bloat treatment, drenches, vaccines, and minerals (DairyBase, 2006).

\section{Selection of Control Variables}

We combine the available data with evidence from the existing empirical literature (e.g., Abdulai and Tietje, 2007; Aubron et al., 2009; Brooks-Pollock and Keeling, 2009; Mounsey, 2015; Robbins et al., 2016; Nuthall and Old, 2017; Ma et al., 2019b) to identify a range of control variables that might influence or moderate engagement with animal health activities.

The DairyBase data set distinguishes between owneroperators and sharemilkers. Broadly speaking, owneroperators own the farm, the plant and machinery, and the herd, and they are ultimately responsible for all managerial decisions on their own farms. Depending on the particular contractual arrangement, sharemilkers may own the herd and some of the farm equipment but do not own the farm. Sharemilkers manage the herd in return for a share of the farm income (Blunden et al., 1997; DairyNZ, 2017; Nuthall and Old, 2017). Given that sharemilkers and owner-operators may have different managerial styles, incentives, and motivations with respect to farm operation and performance, they may have different approaches to animal health prevention and treatment. Thus, we included a farm business type variable to understand how farm ownership structure is related to animal health expenditure. In addition, we also included a multiplicative interaction term for feed use intensification and farm business type to capture their joint effects on animal health expenditure.

Land and cattle are 2 fundamental inputs for dairy production. Although herd size has been positively associated with dairy productivity (Abdulai and Tietje, 2007; Ma et al., 2019a), it is also related to higher risks of animal health problems. For example, a study by Longstreet et al. (2019) has shown that herd size is related to bovine tuberculosis persistence in Great Britain. The relationship between farm size and animal health issues such as lameness, udder health, and Salmonella has also been reviewed in a study by Robbins et al. (2016). Because they may also be related to expenditure on animal health, farm size and herd size are included as control variables in our analysis.

Although empirical research results have been mixed, there is evidence to suggest that breed may be associated with a variety of health outcomes in dairy cattle. For example, a study conducted in Finland found that the odds of lameness was significantly related to breed (Sarjokari et al., 2013), whereas in New Zealand Jersey cattle had a higher risk of axial disease than did Friesians, and Friesians had a higher risk of white line 
Table 2. Variable definition and descriptive statistics

\begin{tabular}{|c|c|c|c|c|c|c|}
\hline Variable & Definition & $\begin{array}{c}\text { No. of } \\
\text { observations }\end{array}$ & Mean & SD & Minimum & Maximum \\
\hline Health expenditure & $\begin{array}{l}\text { Animal health, prevention and treatment, expenditure }(\mathrm{NZ} \$ / \\
\text { cow per year; } 1 \mathrm{NZ} \$=0.64 \text { US } \$)\end{array}$ & 9,752 & 80.76 & 33.89 & 2.03 & 391.74 \\
\hline System 1 & $1=$ farm is recorded as system $1,0=$ otherwise & 9,752 & 0.09 & 0.28 & 0 & 1 \\
\hline System 2 & $1=$ farm is recorded as system $2,0=$ otherwise & 9,752 & 0.27 & 0.45 & 0 & 1 \\
\hline System 5 & $1=$ farm is recorded as system $5,0=$ otherwise & 9,752 & 0.07 & 0.25 & 0 & 1 \\
\hline Business type & $1=$ sharemilking, $0=$ otherwise & 9,752 & 0.26 & 0.44 & 0 & 1 \\
\hline Herd size & The highest number of cows milked & 9,752 & 471.2 & 342.40 & 55 & 8,650 \\
\hline Farm size & $\begin{array}{l}\text { The total pasture or cropping area (or both) available for } \\
\text { milking cows (ha) }\end{array}$ & 9,752 & 159.80 & 109.70 & 25 & 2,280 \\
\hline Dairy breed & $\begin{array}{l}1=\text { crossbreed, } 0=\text { others (e.g., Friesian, Jersey, Ayrshire, } \\
\text { and Brown Swiss) }\end{array}$ & 9,752 & 0.49 & 0.50 & 0 & 1 \\
\hline Unpaid management & $\begin{array}{l}\text { The full-time equivalent of all unpaid (usually family) farm } \\
\text { management }\end{array}$ & 9,752 & 0.76 & 0.39 & 0 & 1 \\
\hline Cash surplus & $\begin{array}{l}\text { Net cash income minus farm working expenses }(\mathrm{NZ} \$ 1,000 / \\
\text { cow per year) }\end{array}$ & 9,752 & 0.88 & 0.57 & -3.03 & 5.20 \\
\hline
\end{tabular}

disease (Lawrence et al., 2011). We therefore included a breed variable to account for potential breed effects on animal health expenditure. With respect to milking frequency, Lean et al. (2008) indicated that the risk of mastitis is affected by milking frequency. Therefore, we included a milking frequency variable to control for the potential effect of this variable on animal health expenditure.

Good stockmanship is essential for achieving high levels of animal health and welfare (Boivin et al., 2003), and labor is a primary component of dairy farm working expenses. Previous studies also have shown that labor plays a positive role in improving dairy productivity (Aubron et al., 2009; Ma et al., 2019a). To control for the influences of labor, we included exogenous variables representing paid and unpaid labor and management. To determine whether a dairy operator's decisions to invest in animal health prevention and treatment are associated with farm profitability, we included a cash surplus variable. Finally, we included 9 year-dummies to control for differences such as weather and the availability and price of supplements that may affect animal health expenditure.

\section{Descriptive Statistics}

Table 2 presents variable definitions and descriptive statistics. It shows that the average expenditure on animal health was NZ\$80.76/cow per year (1NZ\$ $=0.64$ US\$) during the period 2005 to 2014. Although fluctuating, animal health expenditure increased from NZ\$57.12/cow per year to more than NZ\$90/cow per year over the time period (Figure 1). The average score of the intensification variable is 2.89 . The descriptive statistics presented in Table 2 show that only $9 \%$ of farms were pasture-based production system 1 (i.e., zero use of supplementary feed). Around $7 \%$ of farms belonged to production system 5, relying most heavily on imported feed. In our sample, around $26 \%$ of farms are managed by sharemilkers. The average farm size managed by the New Zealand dairy operators in our sample was 160 ha, and the average herd size was 471 during the period. Approximately half of the surveyed farms in our sample milked crossbred cattle, and the majority of farms $(92 \%)$ milked twice a day. The average cash surplus over the time period was NZ\$879/cow per year.

Table 3 presents the distribution of animal health expenditure in New Zealand by production systems, and the mean difference in animal health expenditure per cow between the adoption of a higher system and adoption of pasture-based system 1 . The second column of Table 3 shows that the average animal health expenditure increases from $\mathrm{NZ} \$ 69 /$ cow per year for system 1 to $\mathrm{NZ} \$ 103 /$ cow per year for system 5 . As the focus of this study is the relationship between feed use intensification and animal health expenditure, we first look at 


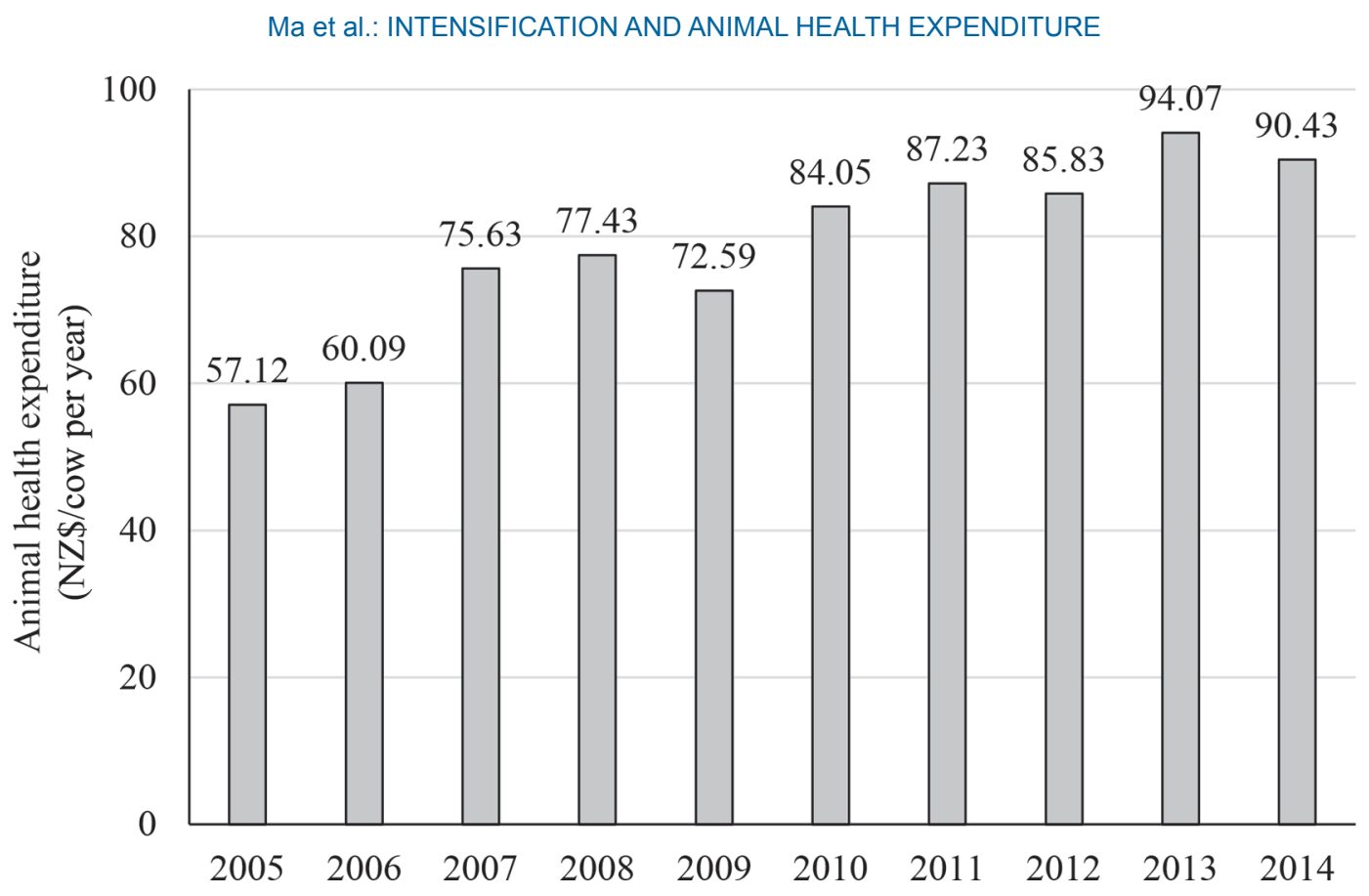

Figure 1. Changes of animal health expenditure over 2005 to $2014(1 \mathrm{NZ} \$=0.64$ US\$).

the Pearson correlation coefficients between our proxies for these variables. The Pearson correlation coefficient is 0.263 between feed use intensification and animal health expenditure, and is statistically significant. The findings suggest that feed use intensification may be associated with animal health expenditure.

The mean difference presented in the third column of Table 3 shows that compared with the adoption of system 1, the adoption of a higher system is associated with a significantly higher expenditure on animal health. However, the findings are not conclusive because the simple descriptive analysis does not control for confounding factors (e.g., farm-level characteristics and year fixed effects) that affect dairy farmers' decisions on animal health expenditure. Therefore, we use a statistical model for panel data to identify how and to what extent feed use intensification is associated with animal health expenditure in dairy production in New Zealand.

\section{Empirical Model}

Panel data statistical techniques were used to empirically investigate the relationship between feed use intensification and animal health expenditure. The following reduced-form animal health expenditure model represents the base specification in this study:

$$
\begin{aligned}
& \log \left(Y_{i t}\right)=\beta_{0}+\beta_{1} I_{i t}+\beta_{2} B_{i t}+\beta_{3}\left(B_{i t} \times I_{i t}\right)+\beta_{4} \log \left(H_{i t}\right) \\
& +\beta_{5} \log \left(F_{i t}\right)+\sum_{n=1}^{6} \beta_{n i t} X_{n i t}+v_{t}+u_{i}+\varepsilon_{i t},
\end{aligned}
$$

where the dependent variable $\log \left(Y_{i t}\right)$ is the log-transformed expenditure of animal health per cow for farm

Table 3. Distribution of animal health expenditure in New Zealand by production systems

\begin{tabular}{lccc}
\hline Intensification & Animal health expenditure & Mean difference & $95 \%$ CI \\
\hline System 1 & 69.26 & & $67.11-71.41$ \\
System 2 & 72.40 & $3.14^{* *}$ & $71.21-73.59$ \\
System 3 & 81.12 & $11.86^{* * *}$ & $80.09-82.16$ \\
System 4 & 89.00 & $19.75^{* * *}$ & $87.56-90.45$ \\
System 5 & 102.74 & $33.48^{* * *}$ & $99.45-106.02$ \\
\hline
\end{tabular}

${ }^{1}$ Mean difference refers to the difference of animal health expenditure between a higher system and pasturebased system 1 .

${ }^{* *} P<0.05,{ }^{* * *} P<0.01$. 
$i$ in year $t ; \beta_{0}$ is an intercept; $I_{i t}$ represents the feed use intensification variable; $B_{i t}$ represents farm business type $(1=$ sharemilkers; $0=$ owner operators $) ; B_{i t} \times$ $I_{i t}$ represents a multiplicative interactive term between farm business type and feed use intensification; $\log \left(H_{i t}\right)$ and $\log \left(F_{i t}\right)$ refer to $\log$-transformed herd size and farm size, respectively; $X_{\text {nit }}(\mathrm{n}=6)$ refers to other control variables, including dairy breed, milking interval, paid labor, unpaid labor, unpaid management, and cash surplus; $\beta_{1}, \beta_{2}, \beta_{3}, \beta_{4}, \beta_{5}$, and $\beta_{\text {nit }}$ are parameters to be estimated; $v_{t}$ controls for unobserved heterogeneities that change over time but do not change across the individual farms; $u_{i}$ is the unobserved heterogeneity that does not change over time; and $\varepsilon_{i t}$ is an error term.

Equation [1] can be estimated with either a fixedeffects model or a random-effects model. The crucial distinction between the 2 models is whether the unobserved individual effect embodies elements that are correlated with regressors in the model. Both specifications have been applied in recent studies (Borchardt et al., 2018; Hadrich et al., 2018; Schorr and Lips, 2018). For example, using a fixed-effects model, Hadrich et al. (2018) have examined how SCC affects milk production. Using a random-effects model and data obtained from the Swiss Farm Accountancy Data Network, Schorr and Lips (2018) analyzed the factors that influence the annual income per family work unit for Swiss dairy farms.

To justify whether the fixed or random-effects model should be used, a Hausman test can be conducted. The null hypothesis $\left(H_{0}\right)$ of the Hausman test is the unique errors $u_{i}$ in Equation [1] are not correlated with the regressors, while the alternative hypothesis $\left(H_{a}\right)$ of the Hausman test is the unique errors $\left(u_{i}\right)$ in Equation [1] are correlated with the regressors. The Hausman statistic is distributed as $\chi^{2}$ and is computed as

$$
H=\left(\beta_{c}-\beta_{e}\right)^{\prime}\left(V_{c}-V_{e}\right)^{-1}\left(\beta_{c}-\beta_{e}\right),
$$

where $\beta_{c}$ is the coefficient vector from the consistent estimator; $\beta_{e}$ is the coefficient vector from the efficient estimator; $V_{c}$ is the covariance matrix of the efficient estimator; and $V_{e}$ is the covariance matrix of the efficient estimator.

For analytical purposes, we set that the fixed-effects model is consistent under $H_{0}$ and $H_{a}$, and the randomfixed-effects model is inconsistent under $H_{a}$ and efficient under $H_{0}$. The rejection of the null hypothesis suggests that the fixed-effects model is preferred to the randomeffects model. Furthermore, the significance of the $F$ test for all $u_{i}=0$, which is reported in the fixed-effects model estimation, would suggest that compared with pooled ordinary least square (POLS) regression model, the fixed-effects model provides consistent estimates. The insignificant $F$-test for all $u_{i}=0$ would suggest that both POLS model and fixed-effects model can provide consistent estimates of the model parameters.

\section{RESULTS AND DISCUSSION}

\section{Results of the Hausman Test}

The results of the Hausman test indicate that the null hypothesis should be rejected [Hausman test: $\chi^{2}$ $\left.(19)=284.86 ; P>\chi^{2}=0.000\right]$, which provides empirical support for the fixed-effects model. The $F$-test for all $u_{i}=0$ is statistically significant, suggesting the presence of unobserved heterogeneity associated with animal health expenditure. Therefore, the fixed-effects model provides consistent estimates but the POLS regression model does not. The $F$-test for all $v_{t}=0$ is statistically significant, suggesting the presence of unobserved heterogeneities that change over time but do not change across the individual farms. These findings generally support the empirical results estimated from the fixed-effects model and will be discussed in the following section.

\section{Empirical Results}

Table 4 presents the results of the empirical analysis. Turning to the variable of our primary interest, the coefficient of the intensification variable is positive and statistically significant. The findings suggest that intensifying dairy farms through additional supplementary feed use is positively and significantly associated with animal health expenditure. One possible explanation for this is that although dairy intensification increases milk production, it also increases the risk of mastitis and metabolic disease, which may lead to increases in animal health expenditure associated with high levels of curative drugs or high prevention costs. This justification is in line with the finding of Lean et al. (2008) and Stafford and Gregory (2008).

The findings also provide insights into other factors that are associated with animal health expenditure. For example, relative to owner operators, sharemilkers appear to spend significantly more on animal health. Under a herd owning sharemilker agreement, the farmer owner provides the land, buildings, and much of the equipment and ensures that the property complies with the requirements of the milk buyer (e.g., dairy company), while the sharemilker provides the herd and some of the equipment, and meets all of the farm operating costs. Given the fact that the herd is the primary asset for sharemilkers, it is likely that they will be relatively highly motivated to invest more heavily in animal 
Table 4. Effect of farm intensification on animal health expenditure: fixed-effects model estimation ${ }^{1}$

\begin{tabular}{lcc}
\hline Variable & Coefficient & $t$-value \\
\hline Intensification & $0.02(0.01)^{* * *}$ & 3.80 \\
Business type & $0.12(0.04)^{* * *}$ & 3.47 \\
Business type $\times$ intensification & $-0.03(0.01)^{* * *}$ & -3.18 \\
Herd size $(l o g)$ & $-0.39(0.04)^{* * *}$ & -9.71 \\
Farm size $(l o g)$ & $0.19(0.04)^{* * *}$ & 4.88 \\
Dairy breed & $-0.00(0.01)$ & -0.26 \\
Milking interval & $0.03(0.02)^{*}$ & 1.93 \\
Paid labor & $0.03(0.01)^{* * *}$ & 4.92 \\
Unpaid labor & $0.01(0.01)$ & 1.38 \\
Unpaid management & $0.00(0.01)$ & 0.31 \\
Cash surplus & $0.00(0.01)$ & 0.90 \\
Year fixed-effect (base $=2005)$ & & \\
2006 & $0.07(0.01)^{* * *}$ & 5.31 \\
2007 & $0.29(0.01)^{* * *}$ & 20.62 \\
2008 & $0.30(0.01)^{* * *}$ & 20.58 \\
2009 & $0.23(0.01)^{* * *}$ & 15.97 \\
2010 & $0.38(0.01)^{* * *}$ & 26.72 \\
2011 & $0.43(0.01)^{* * *}$ & 29.78 \\
2012 & $0.41(0.01)^{* * *}$ & 28.18 \\
2013 & $0.51(0.01)^{* * *}$ & 34.16 \\
2014 & $0.45(0.02)^{* * *}$ & 29.11 \\
Constant & $5.24(0.14)^{* * *}$ & 37.89 \\
$\mathrm{R}^{2}($ within $)$ & 0.26 & \\
$F$-test for all $u_{i}=0$ & $F(3,118,6,614)=8.27 ; P>F=0.00$ \\
$F$-test for all $v_{t}=0$ & $F(20,6,613)=114.37 ; P>F=0.00$ \\
No. of observations & & \\
\hline${ }^{1}$ The dependent variable refers to the log-transformed animal health expenditure measured in NZ $\$ /$ cow per \\
year. Standard errors are in parentheses. $v_{t}$ controls for unobserved heterogeneities that change over time but \\
do not change across the individual farms; $u_{i}$ is the unobserved heterogeneity that does not change over time. \\
${ }^{*} P<0.1, * * * P<0.01$. & & \\
& & \\
& &
\end{tabular}

health. It may also be that sharemilkers spend more time than owner-operators in close proximity to their cows, making it more likely that they will notice and react potential animal health concerns. The multiplicative interaction term between feed use intensification and business type produced a negative and statistically significant coefficient. This finding suggests that for a given sharemilker, those who are intensifying dairy production through supplementary feed use spend less on animal health.

Both herd size and farm size appear to be associated with animal health expenditure. Because these variables have been log-transformed, their coefficients represent elasticities. The negative and statistically significant coefficient for the herd size variable suggests that a $1 \%$ increase in herd size is associated with a $39 \%$ decrease in health expenditure per cow. This may suggest some economies of size are associated with health expenditure; for example, the fixed costs of calling a veterinarian out can be spread over more animals. On the other hand, it may mean that as herds grow the ability to monitor each individual cow decreases, leading to a lower level of expenditure on animal health. These findings are contrasted by those found for another measure of size for the business: area farmed. The positive and statistically significant coefficient on the farm size variable suggests that a $1 \%$ increase in farm size is associated with a $19 \%$ increase in health expenditure per cow. It may be the case that large farms are more difficult to manage, leading to a higher incidence of health issues among milking cows, resulting in higher levels of animal health expenditure.

The positive and significant coefficient on the milking interval variable suggests that, relative to other milking strategies (e.g., once a day or 3 times in 48 $\mathrm{h}$ ), milking twice a day is associated with significantly higher levels of health expenditure per cow. It should be noted that milking twice a day is by far the most prevalent approach in New Zealand and it may be that this frequency of contact enables health issues to be more frequently identified and treated, leading to higher levels of expenditure.

The growth in herd size in the dairy sector has meant that an increasing number of dairy farms depend on hired labor. A question may emerge as to whether the increased use of hired labor has a positive or negative association with herd health expenditure. Our results show a positive relationship between the amount of paid labor (in terms of hours worked) and animal health expenditure. On the one hand, as with increased milking frequency, more labor on the farm might lead to more detection of animal health issues and therefore 
more expenditure. On the other hand, it may be that hired labor is less experienced with animal health issues than those managing the farm, which may lead to greater expenditure as problems develop.

Interestingly, the coefficient on the cash surplus variable is positive but insignificant, even at the $10 \%$ significance level. This is interesting because a visual inspection of the time series data reveals that overall expenditure on veterinary services tends to fall when the milk payout falls. In particular, the low payout years of 2009 and 2012 appear to be associated with lower animal health expenditure in our sample. However, our findings suggest that economic factors (as represented by cash surplus) are not significant drivers of animal health expenditure. This is different from previous studies in the economics literature which indicate that dairy farmers' production behavior is mainly driven by the quest for further profitability (Alvarez et al., 2008; Mounsey, 2015), but consistent with the results of studies in the dairy science and epidemiology literature recently reviewed by Ritter et al. (2017), which support the hypothesis that farmers are not motivated solely by economic factors in their decisions to improve disease management on their farms.

We also measure the association between the 5 production systems and animal health expenditure. The Hausman test was used to compare the validity of the results estimated from a fixed-effects versus a randomeffects model. The findings $\left[\chi^{2}(19)=290.38 ; P>\chi^{2}\right.$ $=0.000]$ justify the use of the fixed-effects model, and the results from this model are presented in Table 5 and discussed below.

The results in Table 5 show that relative to pasturebased production systems, farmers who adopt the most intensive production systems spend significantly more per cow on animal health, while those who adopt production systems 2 to 4 do not. The findings highlight the fact that the positive relationship between feed use intensification and animal health expenditure identified in Table 4 is mainly associated with the most intensive farming system. Among the multiplicative interaction terms, the coefficient on the interaction between business type and production system 5 is negative and statistically significant. The finding suggests that sharemilkers who adopt the most intensive production system spend less on animal health.

\section{Managerial Implications}

Although several studies have concluded that feed use intensification increases the productivity and production efficiency of dairy farms (for example, Hedley et al., 2006; Kompas and Che, 2006; Abdulai and Tietje,
2007; Ma et al., 2018, 2019a), in this paper we provide evidence that feed use intensification also increases animal health expenditure. More detailed assessments of the components of health-related control costs associated with specific disorders (e.g., udder, metabolic reproduction, peripartum, locomotor, and digestion disorders) may help dairy farmers make effective decisions on health management practices.

The finding that high levels of health expenditure are associated mainly with the adoption of farm system 5 underscores the importance of effectively monitoring the health status of cows on the most intensive farms. The effects of feed use intensification are complex because it leads to relatively high stocking rates and increases in other off-farm inputs, which may be associated with various animal health issues, especially on the most intensive farms.

Table 5. Effect of 5 production systems on animal health expenditure: fixed effects model estimation ${ }^{1}$

\begin{tabular}{|c|c|c|}
\hline Variable & Coefficient & $t$-value \\
\hline \multicolumn{3}{|l|}{$\begin{array}{l}\text { Five production systems } \\
\text { (base = system } 1 \text { ) }\end{array}$} \\
\hline System 2 & $-0.02(0.02)$ & -1.32 \\
\hline System 3 & $-0.01(0.02)$ & -0.34 \\
\hline System 4 & $0.03(0.02)$ & 1.21 \\
\hline System 5 & $0.09(0.03)^{* * *}$ & 3.26 \\
\hline Business type & $0.07(0.04)^{* *}$ & 2.02 \\
\hline Business type $\times$ system 2 & $-0.02(0.03)$ & -0.67 \\
\hline Business type $\times$ system 3 & $-0.04(0.03)$ & -1.27 \\
\hline Business type $\times$ system 4 & $-0.06(0.04)$ & -1.48 \\
\hline Business type $\times$ system 5 & $-0.19(0.05)^{* * *}$ & -3.54 \\
\hline Herd size $(\log )$ & $-0.40(0.04)^{* * *}$ & -9.79 \\
\hline Farm size (log) & $0.18(0.04)^{* * *}$ & 4.85 \\
\hline Dairy breed & $-0.00(0.01)$ & -0.26 \\
\hline Milking interval & $0.03(0.02)^{* *}$ & 2.12 \\
\hline Paid labor & $0.03(0.01)^{* * *}$ & 4.98 \\
\hline Unpaid labor & $0.01(0.01)$ & 1.41 \\
\hline Unpaid management & $0.00(0.01)$ & 0.18 \\
\hline Cash surplus & $0.00(0.01)$ & 0.88 \\
\hline 2006 & $0.07(0.01)^{* * *}$ & 5.25 \\
\hline 2007 & $0.28(0.01)^{* * *}$ & 20.51 \\
\hline 2008 & $0.30(0.01)^{* * *}$ & 20.51 \\
\hline 2009 & $0.23(0.01)^{* * *}$ & 15.91 \\
\hline 2010 & $0.38(0.01)^{* * *}$ & 26.62 \\
\hline 2011 & $0.43(0.01)^{* * *}$ & 29.64 \\
\hline 2012 & $0.41(0.01)^{* * *}$ & 28.11 \\
\hline 2013 & $0.51(0.01)^{* * *}$ & 34.11 \\
\hline 2014 & $0.45(0.02)^{* * *}$ & 29.07 \\
\hline Constant & $5.33(0.14)^{* * *}$ & 38.40 \\
\hline $\mathrm{R}^{2}$ (within) & 0.26 & \\
\hline$F$-test for all $u_{i}=0$ & $F(3,118,6,607)=8$ & $F=0.00$ \\
\hline$F$-test for all $v_{t}=0$ & $F(26,6,607)=88.78$ & $F=0.000$ \\
\hline No. of observations & 9,752 & \\
\hline
\end{tabular}

${ }^{1}$ The dependent variable refers to the log-transformed animal health expenditure measured in NZ\$/cow per year. Standard errors are in parentheses. $v_{t}$ controls for unobserved heterogeneities that change over time but do not change across the individual farms; $u_{i}$ is the unobserved heterogeneity that does not change over time.

${ }^{* *} P<0.05,{ }^{* * *} P<0.01$. 
Our findings indicate that animal health expenditure increases, on average, with labor use intensity. One possible explanation for this positive association is that animal health issues are more likely to be detected and treated as the number of workers increases. It also may be the case that cows on more labor intensive farms are under more metabolic pressure, and therefore more prone to conditions that require supplements or treatment. Teasing out the underlying reason for the association is an interesting area for future study. The finding that animal health expenditure is not strongly associated with cash surplus may help allay concerns around the welfare of dairy cows during periods of low dairy profitability.

\section{CONCLUSIONS}

The results of this study suggest that feed use intensification significantly increases health expenditure per cow, and show the positive relationship is mainly driven by the expenditure of the most intensive farm systems. Our findings highlight the fact that the trend toward intensification is likely to be related to health and welfare outcomes for the stock, and therefore requires particular skill in herd health management. In dairy production, and as measured in this study, animal health expenditure is used for both disease prevention and disease treatment. Thus, to provide more insight into the exact nature of the relationship between intensification and animal health outcomes, a more detailed breakdown of animal health expenditure and a more direct indicator of animal health outcomes are necessary.

\section{ACKNOWLEDGMENTS}

This research is one of a series of analyses in the Marginal Imperative Project funded by New Zealand dairy farmers through DairyNZ and the Ministry for Primary Industries in the Transforming the Dairy Value Chain Primary Growth Partnership programme.

\section{REFERENCES}

Abdulai, A., and H. Tietje. 2007. Estimating technical efficiency under unobserved heterogeneity with stochastic frontier models: Application to northern German dairy farms. Eur. Rev. Agric. Econ. 34:393-416.

Alvarez, A., J. del Corral, D. Solís, and J. A. Pérez. 2008. Does intensification improve the economic efficiency of dairy farms? J. Dairy Sci. 91:3693-3698.

Aubron, C., H. Cochet, G. Brunschwig, and C. H. Moulin. 2009. Labor and its productivity in Andean dairy farming systems: A comparative approach. Hum. Ecol. 37:407-419.

Basset-Mens, C., S. Ledgard, and M. Boyes. 2009. Eco-efficiency of intensification scenarios for milk production in New Zealand. Ecol. Econ. 68:1615-1625.
Bava, L., A. Sandrucci, M. Zucali, M. Guerci, and A. Tamburini. 2014. How can farming intensification affect the environmental impact of milk production? J. Dairy Sci. 97:4579-4593.

Blunden, G., W. Moran, and A. Bradly. 1997. "Archaic" relations of production in modern agricultural systems: The example of sharemilking in New Zealand. Environ. Plann. A 29:1759-1776.

Boivin, X., J. Lensink, C. Tallet, and I. Veissier. 2003. Stockmanship and farm animal welfare. Anim. Welf. 12:479-492.

Borchardt, S., A. Pohl, P. D. Carvalho, P. M. Fricke, and W. Heuwieser. 2018. Short communication: Effect of adding a second prostaglandin $\mathrm{F}_{2 \alpha}$ injection during the Ovsynch protocol on luteal regression and fertility in lactating dairy cows: A meta-analysis. J. Dairy Sci. 101:8566-8571.

Brooks-Pollock, E., and M. Keeling. 2009. Herd size and bovine tuberculosis persistence in cattle farms in Great Britain. Prev. Vet. Med. 92:360-365.

Cabrera, V. E., D. Solís, and J. del Corral. 2010. Determinants of technical efficiency among dairy farms in Wisconsin. J. Dairy Sci. 93:387-393.

Chobtang, J., S. F. Ledgard, S. J. McLaren, and D. J. Donaghy. 2017. Life cycle environmental impacts of high and low intensification pasture-based milk production systems: A case study of the Waikato region, New Zealand. J. Clean. Prod. 140:664-674.

DairyNZ. 2017. DairyNZ Economic Survey 2015-16. DairyNZ, Hamilton, New Zealand.

DairyBase. 2006. DairyBase Report Description Handbook. DairyNZ, Hamilton, New Zealand.

FAO. 2004. The ethics of sustainable agricultural intensification. Food and Agriculture Organization of the United Nations, Rome, Italy.

Foote, K. J., M. K. Joy, and R. G. Death. 2015. New Zealand dairy farming: Milking our environment for all its worth. Environ. Manage. 56:709-720.

Hadrich, J. C., C. A. Wolf, J. Lombard, and T. M. Dolak. 2018. Estimating milk yield and value losses from increased somatic cell count on US dairy farms. J. Dairy Sci. 101:3588-3596.

Hedley, P., E. S. Kolver, C. Glassey, B. Thorrold, A. van Bysterveldt, and K. Macdonald. 2006. Achieving high performance from a range of farm system. South Island Dairy Event.

Kompas, T., and T. N. Che. 2006. Technology choice and efficiency on Australian dairy farms. Aust. J. Agric. Resour. Econ. 50:65-83.

Lawrence, K. E., R. N. Chesterton, and R. A. Laven. 2011. Further investigation of lameness in cows at pasture: An analysis of the lesions found in, and some possible risk factors associated with, lame New Zealand dairy cattle requiring veterinary treatment. J. Dairy Sci. 94:2794-2805.

Lean, I. J., C. T. Westwood, and M. C. Playford. 2008. Livestock disease threats associated with intensification of pastoral dairy farming. N. Z. Vet. J. 56:261-269.

Longstreet, P., S. Brooks, and E. S. Gonzalez. 2019. Internet addiction: When the positive emotions are not so positive. Technol. Soc. 57:76-85. https://doi.org/10.1016/j.techsoc.2018.12.004.

Ma, W., K. Bicknell, and A. Renwick. 2019a. Feed use intensification and technical efficiency of dairy farms in New Zealand. Aust. J. Agric. Resour. Econ. 63:20-38.

Ma, W., A. Renwick, and K. Bicknell. 2018. Higher intensity, higher profit? Empirical evidence from dairy farming in New Zealand. J. Agric. Econ. 69:739-755.

Ma, W., A. Renwick, and B. Greig. 2019b. Modelling the heterogeneous effects of stocking rate on dairy production: An application of unconditional quantile regression with fixed effects. Appl. Econ. 00:1-12.

Mounsey, Z. 2015. Analysis of Production Systems in the New Zealand Dairy Industry. DairyNZ Report, Hamilton, New Zealand.

Nuthall, P. L., and K. M. Old. 2017. Farm owners' reluctance to embrace family succession and the implications for extension: The case of family farms in New Zealand. J. Agric. Educ. Ext. 23:39-60.

Ritter, C., J. Jansen, S. Roche, D. F. Kelton, C. L. Adams, K. Orsel, R. J. Erskine, G. Benedictus, T. J. G. M. Lam, and H. W. Barkema. 2017. Invited review: Determinants of farmers' adoption 
of management-based strategies for infectious disease prevention and control. J. Dairy Sci. 100:3329-3347.

Robbins, J. A., M. A. G. von Keyserlingk, D. Fraser, and D. M. Weary. 2016. INVITED REVIEW: Farm size and animal welfare. J. Anim. Sci. 94:5439-5455

Rushton, J. 2011. The Economics of Animal Health and Production. CABI, Wallingford, United Kingdom.

Salou, T., C. Le Mouël, and H. M. G. van der Werf. 2017. Environmental impacts of dairy system intensification: The functional unit matters! J. Clean. Prod. 140:445-454.

Sarjokari, K., K. O. Kaustell, T. Hurme, T. Kivinen, O. A. T. Peltoniemi, H. Saloniemi, and P. J. Rajala-Schultz. 2013. Prevalence and risk factors for lameness in insulated free stall barns in Finland. Livest. Sci. 156:44-52.

Schorr, A., and M. Lips. 2018. Influence of milk yield on profitabilityA quantile regression analysis. J. Dairy Sci. 101:8350-8368.
Stafford, K. J., and N. G. Gregory. 2008. Implications of intensification of pastoral animal production on animal welfare. N. Z. Vet. J. $56: 274-280$.

Sumner, C. L., M. A. G. von Keyserlingk, and D. M. Weary. 2018. Perspectives of farmers and veterinarians concerning dairy cattle welfare. Anim. Front. 8:8-13.

Yates, L., J. Dotterer, and A. McDermott. 2010. The consequences of variability in pasture growth and milk price on dairy farm profitability. Pages 244-248 in Proceedings of the 4th Australasian Dairy Science Symposium, Christchurch.

\section{ORCIDS}

Wanglin Ma @ https://orcid.org/0000-0001-7847-8459 